\title{
Carbon Nanotubes Sensors for Gases Detection in Oil Industry
}

Amin D. Thamira*, Ali S.Hasan ${ }^{* *}$, Raheem G. Kadhim, Watheq G. Bakheet ${ }^{* * * *}$ and Hamid I.

\section{Abbood $^{* * *}$}

*Department of Production Engineering and Metallurgy, University of Technology,

${ }^{* *}$ College of Engineering, University of Babylon

${ }^{* * *}$ Department of Physics - College of Science, University of Babylon,

**** Oil Products Distribution Company/Ministry of Oil.

Corresponding Author Email: alisalahphy@yahoo.com

\section{$\underline{\text { Abstract }}$}

One of the most important uses of carbon nanotubes (CNTs) as a nanosensor for various polluted gases resulting from the burning of petroleum derivatives containing sulfur compounds or extracted from the gases associated with petroleum, which are isolated by heat.

In this investigation, we tested the adhesion of gas molecules connected with oil: we examined the adhesion of gas molecules connected with oil: sulfur dioxide $\left(\mathrm{SO}_{2}\right)$ and hydrogen sulphide $\left(\mathrm{H}_{2} \mathrm{~S}\right)$ on the surface of $((5,0)$ zigzag and length $(100 \mathrm{~nm}))$ CNTs using DFT calculations to explore the high sensitivity to nanosensor for these molecules, which have gotten awesome consideration because of environmental and industrial considerations.

From the results obtained in this study geometry optimization (structural properties) for nanosensor for useful assention with trial information. While the electronic properties included calculate total energy, HOMO energies, LUMO energies, ionization potential, electron affinity, potential electronic chemical, electronegativity, electrochemical hardness and electronic softness, also, the energy gap of the sensors under study has been calculated and the energy gap varies as stated by the type of gases to be detected. Moreover, we used orbital analysis counting the DOS to finding out the possible orbital hybridization between molecules and CNTs. From these results, we can say that the CNTs under study $((5,0)$ zigzag and the length $(100 \mathrm{~nm}))$ has a high susceptibility to being an effective nanosensor for the gas molecules connected with the oil. This type of sensor $\left(\mathrm{CNTs} / \mathrm{SO}_{2}\right.$ or $\left.\mathrm{H}_{2} \mathrm{~S}\right)$ is standout amongst those a large portion essentialpersonal protective equipment that is to warn the person of the presence of gases associated with oil, especially in areas of normal gas extraction.

Keywords: CNTs; Nanosensor ; Structural and Electronic properties;Oil industry. 


\section{متحسسات من أنابيب الكاريون النانوية للكشف عن الغازات في الصناعات النفطية}

من أهم استخدامات أنابيب الكاربون النانوية (CNTs) كمستشعر نانوي للغازات الملوثه المختلفة الناتجة من حرق المشتقات النفطية التي تحوي على مركبات الكبريت أو المستخرجة من الغاز ات المصاحبه للبترول والذي يتم فصلها بالحرارة. في هذه

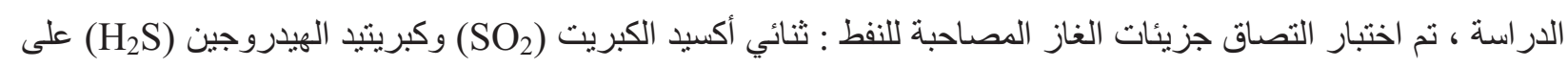

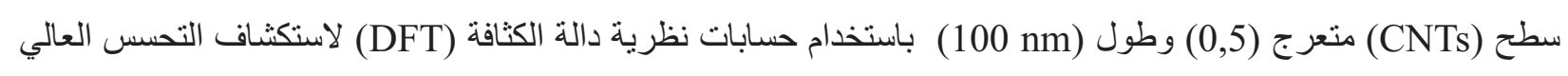
للمستشعر النانوي لهذه الجزيئات التي اخذت اهتماماً كبير انتيجة الاعتبار ات البيئية والصناعية لها. من النتائج التي نم الحصول بله

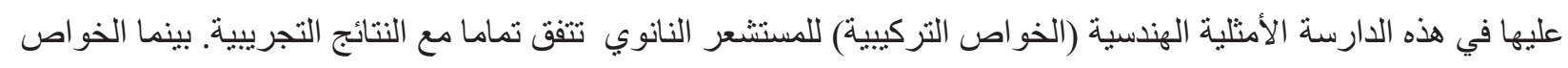
الالكترونية تضمنت حساب الطاقة الكلية، طاقات المدار ات الجزيئية الأعلى المشغولة (HOMO)، طاقات المدار ات الجزيئية

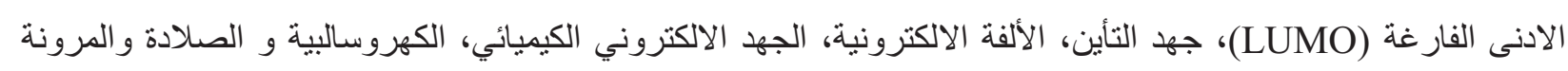

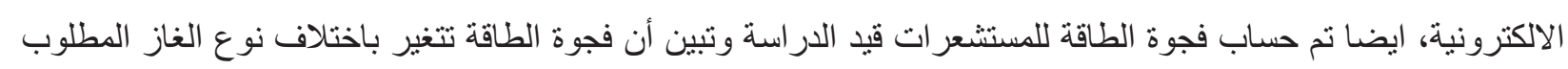
الكثف عنه. بالإضافة الى ذلك، قمنا بحساب كثافة الحالات (DOS) لمعرفة التهجين المداري المحتمل بين هذه الجزيئات

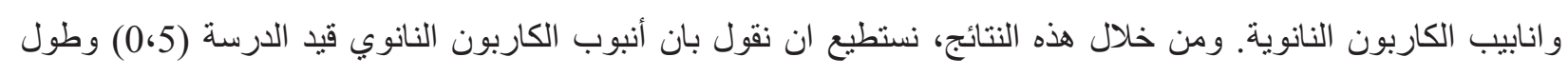

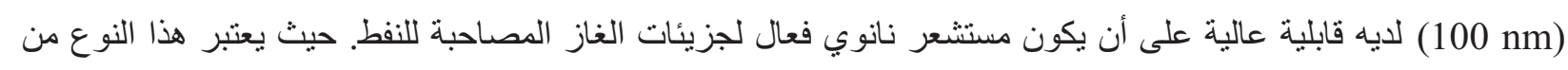
المتحسات (CNTs/H2S or $\mathrm{SO}_{2}$ أحد أهم معدات الحماية الثخصية التي تعمل على تحذير الثخص من وجود الغازات المصاحبة للنفط وخصوصا في مناطق استخر اج الغاز الطبيعي. الكلمات الدالة: أنابيب الكربون النانوية؛ متحسسات نانوية؛ الخصائص الالكترونية و التركيبية؛ الصناعات النفطية

\section{Introduction}

Nanoscience and nanotechnology have created an incredible arrangement of excitement, activity, promise and expectation in the previous couple of years. The immense academic interest has resulted in many publications and patents [1]. Commercial interest has stimulated activities to produce practical nanomaterials and nanodevices, including sensors [2]. This audit examines nanotechnology and sensors with an emphasis on CNTs and chemical and biochemical sensors made from carbon nano-tubes [3]. In general, the literature on nanostructures, nanotubes, CNTs and sensor appli-cations is growing exponentially $[4,5]$. The literature on nanotubes for all applications is exploding and, like most new technologies, much of the growth has been first in the logical and engineering novelties and later in more applied studies and ultimately realistic applications. There have been various surveys of the elec-trical and mechanical properties of CNTs and their planning $[4,6]$.

Late improvement of nanotechnology has made colossal potential to construct exceedingly touchy, minimal effort, convenient sensors with low power utilization. The to a great degree high surface-to-volume proportion and empty structure of nanomaterials is perfect for gas atoms 
adsorption and capacity. In this way, gas sensors in light of nanomaterials, for example CNTs, nanowires, nanofibers, and nanoparticles, have been examined widely [7, 8].

Carbon nanotubes, since been initially found by Iijima in 1991 [8], have drawn the most research intrigues due to their novel geometry, morphology, and properties. Their planning, properties, (for example, electronic, mechanical, warm, and optical properties), and applications on different fields are altogether examined seriously. Theoretical and simulation works have additionally been directed to comprehend this nanoscaled material and related wonder [9].

Carbon nanotubes have a place with the group of fullerene structures. There are two kinds of nanotubes: (SWCNTs) and (MWCNTs). A SWCNT can be considered as a one-molecule thick layer of graphite moved up into a consistent barrel with a measurement of a few nanometers, and length on the request of $1-100$ microns [10]. MWCNTs comprise of various layers of graphite wrapped up together to frame a tube shape, having a similar focal hub. The structure of carbon nanotubes gives them naturally one of a kind electrical, physical, and chemical properties. Mechanically, CNTs are the most grounded and stiffest strands that are known right now due to the $\mathrm{C}-\mathrm{C}$ bond. Thermally, CNTs have high warm solidness in both vacuum and air. As far as electrical properties, CNTs can be either metallic or semiconducting, contingent on the tube breadth and the chirality (the bearing in which the graphite sheet is moved to shape the tube) [8, 10]. The chirality is normally spoken to by a whole number combine (n,m). Nanotubes with (n$\mathrm{m}=3 \mathrm{j}$ ( $\mathrm{j}$ being a nonzero whole number) are metallic while all the others are semiconducting. The dielectric property of nanotubes is very anisotropic because of their about one-dimensional structures, which may empower nanotubes to convey high streams with immaterial warming impact $[12,13]$. The point of this work was to study the adsorption of associated petroleum gas molecules including $\mathrm{H} 2 \mathrm{~S}$ and $\mathrm{SO}_{2}$ molecules on (0.5) zigzag SWCNT system. In order to explore the feasibility of using SWCNT as selective gas nanosensor, the energetic and electronic properties of the CNT with the gas molecules was investigated based on a first-principles of the DFT calculations.

For deeply understand the changes of electronic properties of SWCNT with above gas molecules, the DOS analysis was used test the impact of the associated petroleum gas molecules on electronic properties of CNT - based gas nanosensor. Figure 1 shows the structural relation between a graphene paper and a nanotube [13]. 


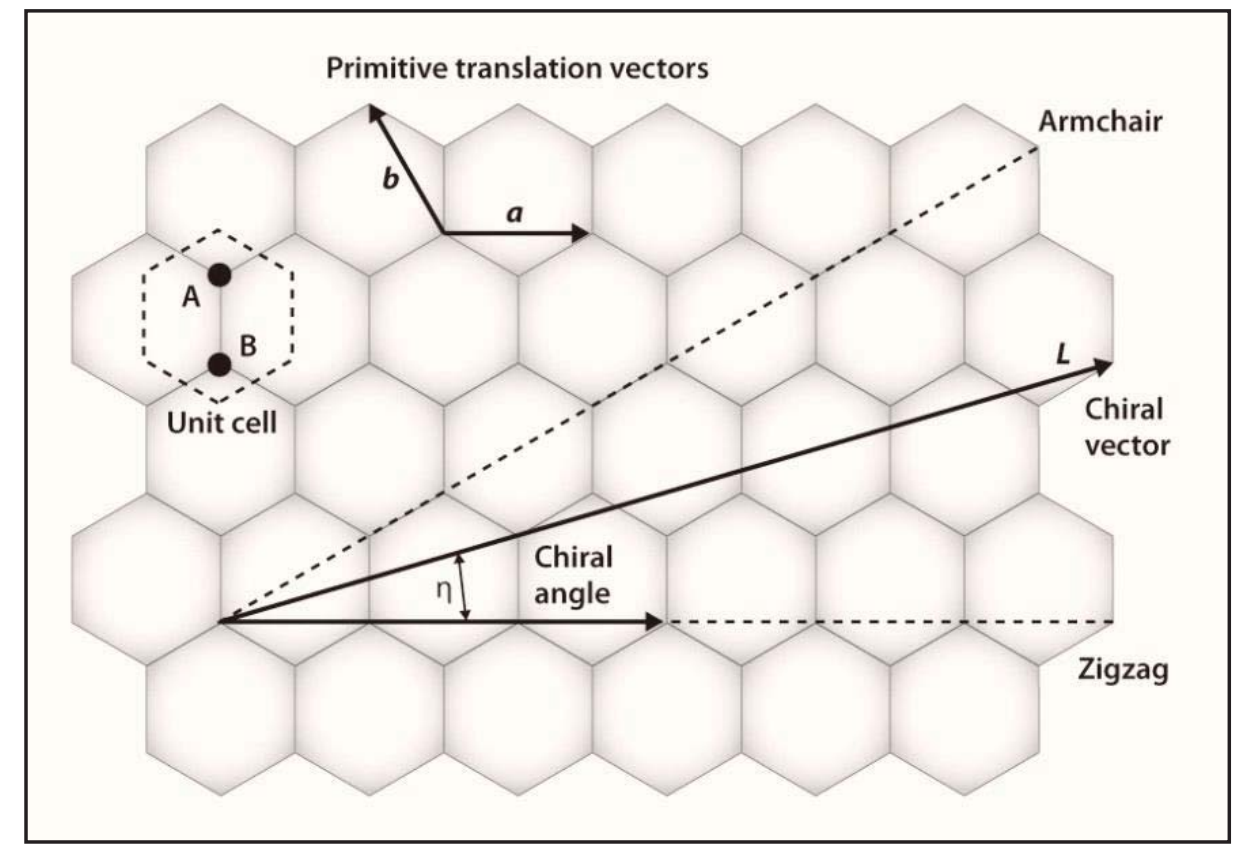

Fig. (1) Structural relation between a graphene sheet and a nanotube[13]

\section{Theoretical Methods}

Figure (2) represents the molecules under study. All the computational examinations were completed utilizing the DFT techniques executed in the Gaussian 09 suite of projects [14]. Herein, we select the $(5,0)$ CNT system as a model nanosensor, which consists 50 carbon atom, , $4.214 \AA$ the diameter of the tube, $10 \AA$ length of tube, and $1.42 \AA$ the average length of the C-C bond.

The molecular properties of the compounds have been computed by DFT using the standard 6-31 G(d) basis set. In the DFT counts the Lee, Yang and Parr connection functional [15] is utilized together with Becke's three parameters [16] exchange practical B3LYP. Conformational investigation of the particles has been performed to have a thought regarding the most reduced vitality structures of the species. The geometry advancement was performed at the B3LYP DFT with a similar basis set $[14,17]$.

Harmonic vibration frequencies were registered at a similar level of hypothesis. The cross breed practical B3LYP has appeared to be profoundly effective for count the electronic properties, for example, ionization possibilities, electronic states and vitality holes [18-20]. The DFT allotments the electronic vitality as $\mathrm{E}_{=}=\mathrm{E}_{\mathrm{T}}+\mathrm{E}_{\mathrm{V}}+\mathrm{E}_{\mathrm{J}}+\mathrm{E}_{\mathrm{XC}}$, where $\mathrm{E}_{\mathrm{T}}, \mathrm{E}_{\mathrm{V}}$, and $\mathrm{E}_{\mathrm{J}}$ are the electronic active vitality, the electron atomic fascination and the electron-electron repugnance terms separately. The electron connection is considered in DFT by means of the trade relationship term $\mathrm{E}_{\mathrm{XC}}$, 
which incorporates the trade vitality emerging from the counter symmetry of the quantum mechanical wave work and the dynamic relationship in the movement of individual electrons; it makes DFT predominant over the regular HF system [14].

In this examination, the more relevant electronic potential (IP), electron affinities (EA), chemical potential $(\mu)$ it is the negative of electro negativity $(\chi)$, hardness $(\eta)$ and softness $(S)$ were calculated. The HOMO and LUMO vitality was also utilized to valuation the IP and EA in the scope of Koopmans' hypothesis[21, 22]:

$I P==-E_{H O M O}, E A==-E_{L U M O}$

Inside the scope of the DFT, one of the universal quantities is chemical potential $(\mu)$, which will be measures those escaping inclination for an electronic cloud, Furthermore equals those incline of the vitality versus $N($ number of electrons) curve at outside potential v(r) [23]:

$\mu=\left(\frac{\partial E}{\partial N}\right)_{V(\vec{r}), T}$

Limited divergence estimation to chemical potential gives,

$\mu \approx \frac{1}{2}\left(E_{\text {HOMO }}+E_{\text {LUMO }}\right) \approx-\frac{1}{2}(I P+E A)$

$X=\frac{(I P+E A)}{2}$

Where, $X$ : is electronegativity.

The theoretical definition about chemical hardness has been provided by the DFT as the second subordinate from claiming electronic vitality for admiration to those number from claiming electrons $\mathrm{N}$, for a constant external potential $\mathrm{v}(\mathrm{r})[22,23]$ :

$\eta=\frac{1}{2}\left(\frac{\partial^{2} E}{\partial N^{2}}\right)_{V(\vec{r})}$

Limited divergence estimation to chemical hardness gives,

$\eta=\frac{(\mathrm{IP}-\mathrm{EA})}{2}$

For Insulator and semiconductor, hardness is half of the energy gap ( $\left.\mathrm{E}_{\text {HOMO }}-\mathrm{E}_{\mathrm{LUMO}}\right)$ and the softness is given as [22]:

$S=\frac{1}{2 \eta}\left(\frac{\partial^{2} N}{\partial E^{2}}\right)_{V(\vec{r})}=\left(\frac{\partial N}{\partial \mu}\right)_{V(\vec{r})}$ 


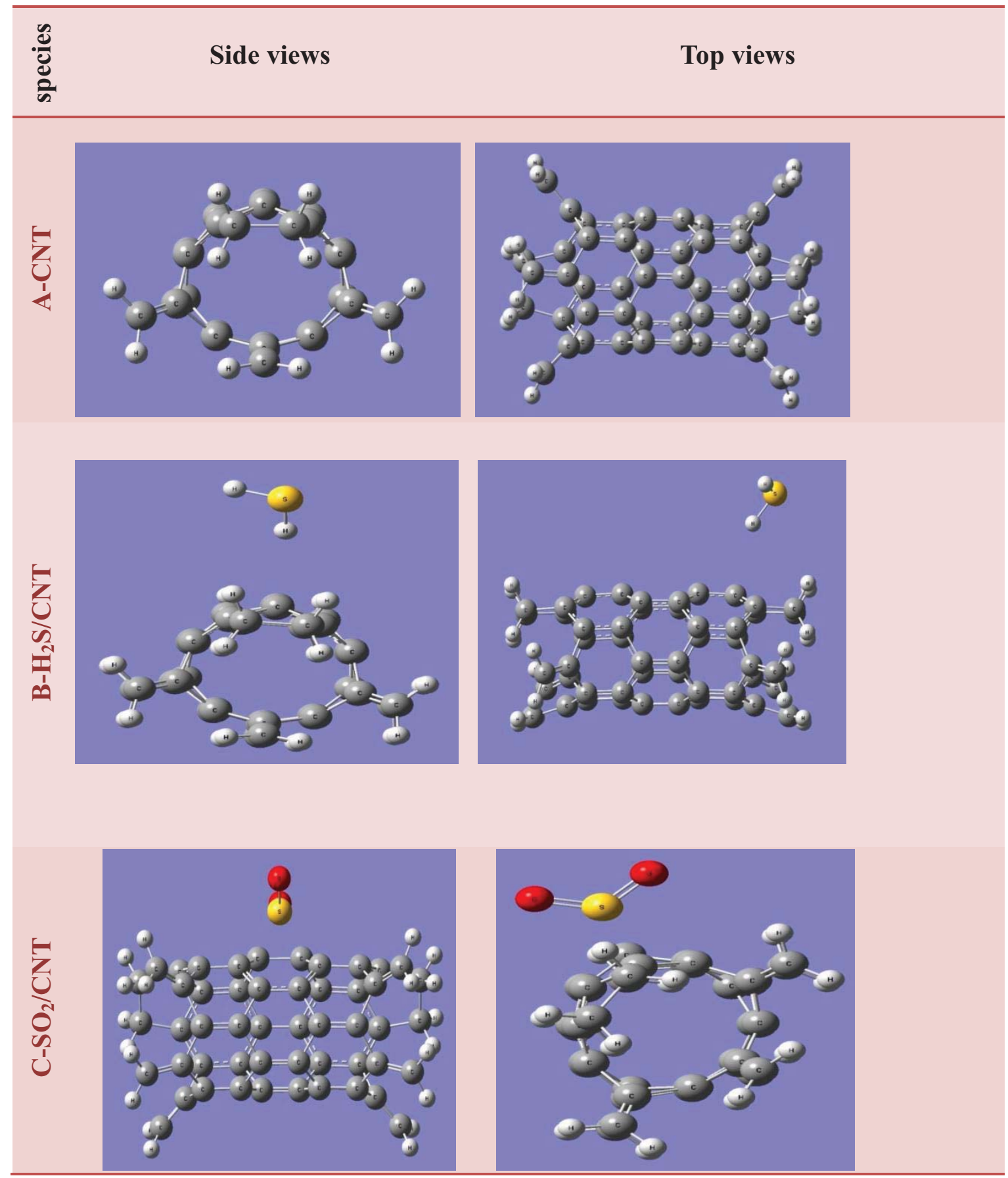

Fig. (2) (A-B-C) Structures of Carbon Nanotubes Sensors in this work (Carbon $\equiv$ gray, Hydrogen $\equiv$ white, Sulfur $\equiv$ yellow, Oxygen $\equiv$ red). 


\section{Results and Discussion}

Figure (2) illustrates the geometrical optimization of the suggested structures in this research, these structures are included three species; $\mathrm{CNT}, \mathrm{H}_{2} \mathrm{~S} / \mathrm{CNT}$ and $\mathrm{SO}_{2} / \mathrm{CNT}$ Sensors. The results got in this investigation geometry optimization (structural properties) for nanosensor in great concurrence with test information. The carbon-carbon bond of the relaxed structures under study are in the ranges $(\mathrm{C}-\mathrm{C}: 1.526 ; \mathrm{C}=\mathrm{C}: 1.352 ; \mathrm{C} \equiv \mathrm{C}: 1.421)$, this result is in a good agreement with those of aromatic rings [22, 24].

Table (1) shows the ground state calculations of the CNTs Sensors at the minimum energy. These calculations are included the total energy in a. u, (IP) and (EA) in eV calculated due to Koopman's theorem, forbidden energy gap $\left(\mathrm{E}_{\mathrm{g}}\right)$ in $\mathrm{eV},(\mathrm{S})$ in $(\mathrm{eV})^{-1},(\eta)$ in $\mathrm{eV},(\mu)$ in $\mathrm{eV}$ and $(\chi)$ in $(\mathrm{eV})$. Also, the calculations are included the DOS of CNTs.

Table (1) Electronic Properties of CNTs.

\begin{tabular}{|c|c|c|c|c|c|c|c|c|c|}
\hline Tittlt & $\mathrm{E}_{\mathrm{T}}$ & $\mathrm{W}$ & $\mathrm{S}$ & $\eta$ & $\mathrm{X}$ & $\mu$ & $\mathrm{EA}$ & $\mathrm{IP}$ & $\mathrm{E}_{\mathrm{g}}$ \\
\hline $\mathbf{C N T}$ & - & 8.458 & 0.529 & 0.945 & 3.998 & -3.998 & 3.053 & 4.943 & $\mathbf{1 . 8 9 0}$ \\
& $\begin{array}{c}1916.870472 \\
\mathbf{H}\end{array}$ & & & & & & & & \\
\hline & - & 11.127 & 0.704 & 0.710 & 3.975 & -3.975 & 3.265 & 4.685 & $\mathbf{1 . 4 2 0}$ \\
\hline $\mathbf{S O}_{2} / \mathbf{C N T}$ & - & 11.613 & 0.659 & 0.759 & 4.198 & -4.198 & 3.439 & 4.957 & $\mathbf{1 . 5 1 8}$ \\
& 246.258341 & & & & & & & & \\
\hline & 2465.385421 & & & & & & & & \\
\hline
\end{tabular}

The total vitality $\mathrm{E}_{\mathrm{T}}$ of CNTs under stydy is very small as we see in Figure (3), this result is a reflection of the binding energy of each structure.Note from Figures (4 and 5) that both the IP and the EA differ in value because of the type of gas required to be detected, where IP and EA for $\mathrm{SO}_{2} / \mathrm{CNT}$ are higher than $\mathrm{H}_{2} \mathrm{~S} / \mathrm{CNT}[24,25]$.

The above results are correspond to the $S$ and $\eta$ of the structures, the results showed that the CNT has large value of $\eta$ and small value of $S$, but, when sensing gases, the values are close and are indicative of the success of gas exploration work for the type of gases utilized as a part of this examination as we see in Figures (6 and 7). The calculated X refer to that the CNTs can interacts with other species in the medium, and means large escaping tendency as we see in Figure (8) [20, 22, 26].

The outcomes demonstrate an decline in the $E_{g}$ values when sensing the gases. This is an 
indication of the approximation of the HOMO and LUMO values starting with one another and thus the possibility of electronic transitions between the valence and conductivity band as we see in Figure (9). Also, from Figure (10), we see that the distribution is similar to the charges at sensor CNT due to the absence of gas to detect it. In the vicinity from claiming gasses $\mathrm{H}_{2} \mathrm{~S}$ and $\mathrm{SO}_{2}$, there is a clear difference in the electronic distribution of the charges due to the drag of charges $[22,24]$.

The DOS legislates a significant number physical properties and hence assumes a paramount part done robust state material science. It may be vital on have the ability with anticipate how the DOS will behave for different nanostructure geometries. The DOS of a framework portrays the number for states for every interim for vitality during each vitality level that are available to be occupied. Those appropriation about vitality between indistinguishable twin particles relies To a limited extent upon know what number of accessible states there need aid over a provided for vitality interim [27]. The DOS of CNTs Sensors as a function of Fermi energy was calculated by employing the DFT at hybrid B3 LYP level with 6-31G (d) basis set and shown in Figure (11). The observed nonzero DOS demonstrates an limited number for states. The band gap change from the interaction of $\mathrm{H}_{2} \mathrm{~S}, \mathrm{SO}_{2}$ molecules with $\mathrm{CNT}$ is close because the band gaps of $\mathrm{H}_{2} \mathrm{~S}_{2} \mathrm{SO}_{2}$ molecules are so near to each other. From the distribution of the DOS, one can estimate a characteristic amplitude of the fluctuations of 6 and $-3,7 \mathrm{eV}[28,29]$.

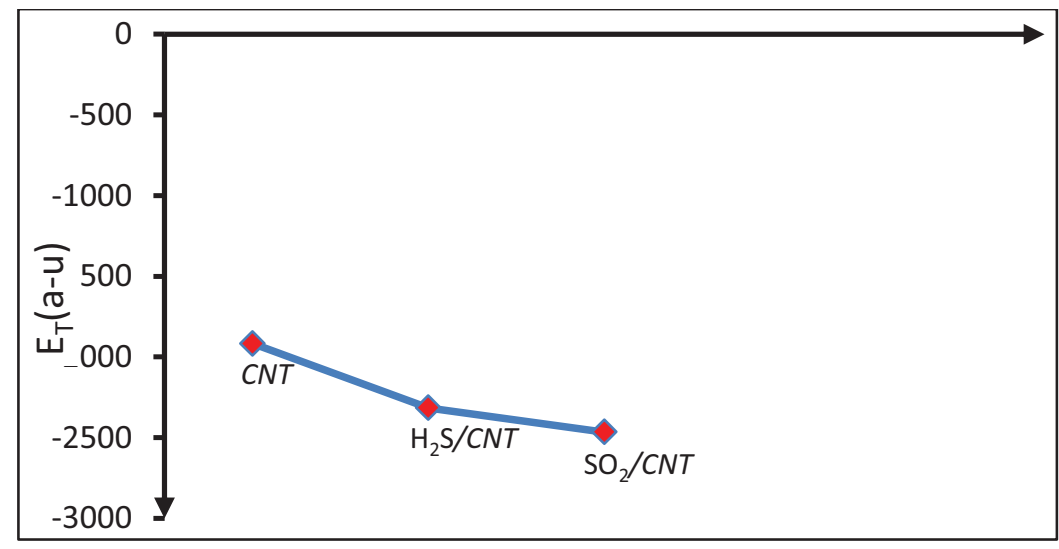

Fig. (3) The total energy in a.u of the CNTs Sensors in this work. 


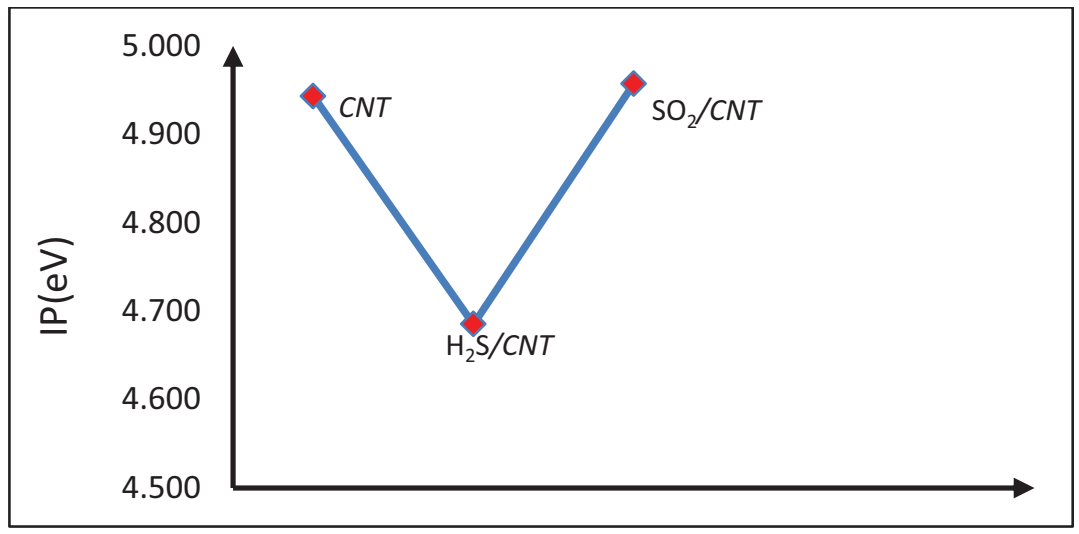

Fig. (4) The ionization potential in $\mathrm{eV}$ of the CNTs Sensors in this work.

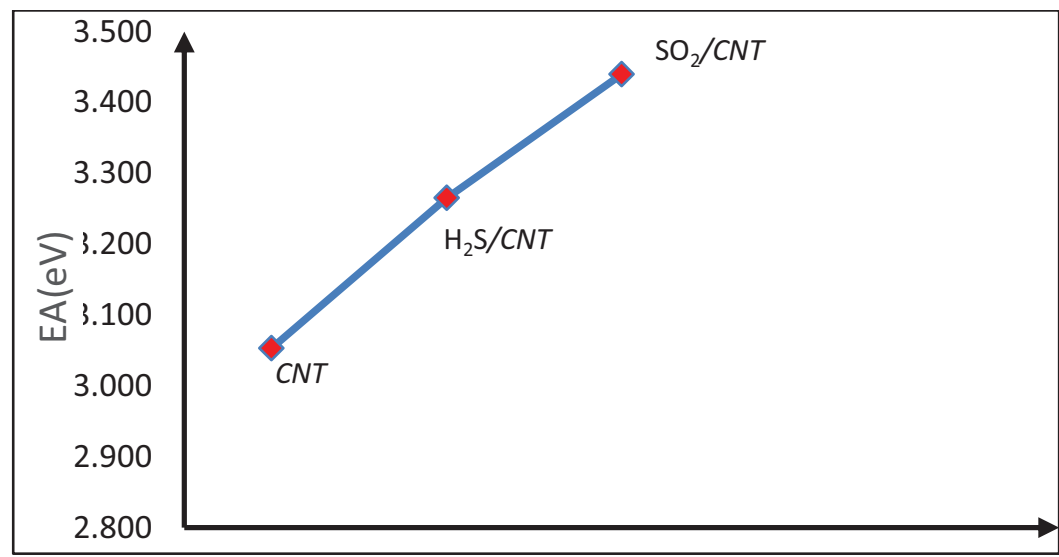

Fig. (5) The electron affinity in $\mathrm{eV}$ of the CNTs Sensors in this work.

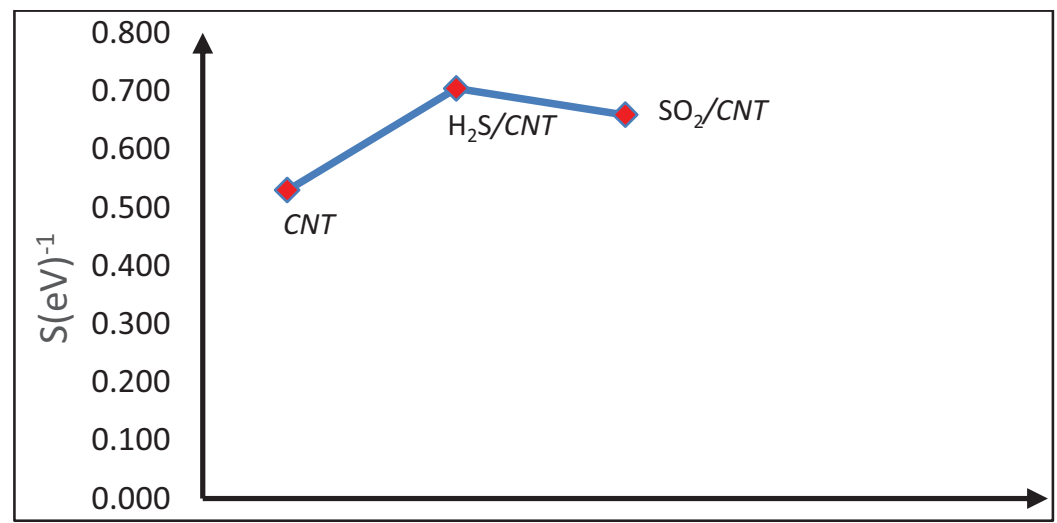

Fig. (6) The electronic softness in $(\mathrm{eV})^{-1}$ of the CNTs Sensors in this work. 


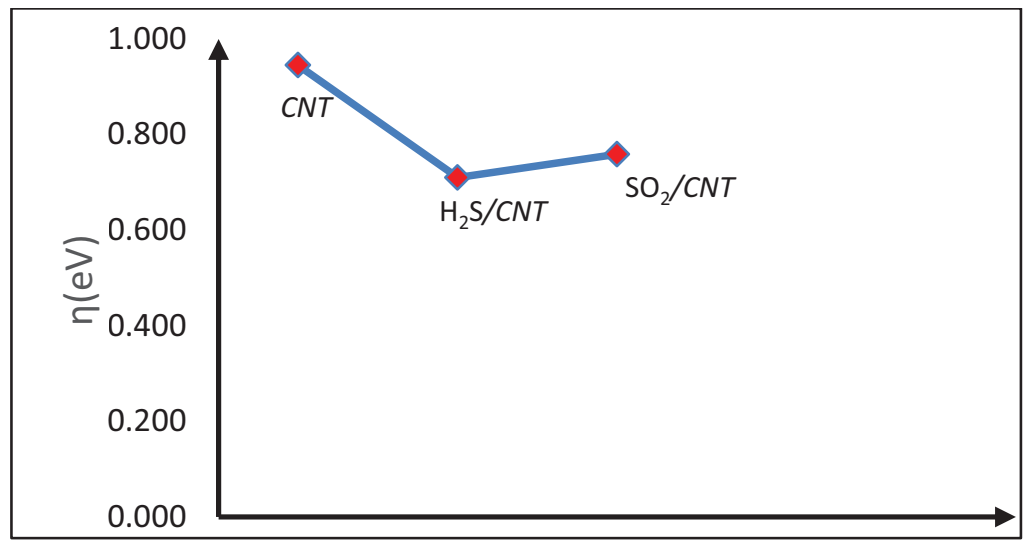

Fig. (7) The electrochemical hardness in eV of the CNTs Sensors in this work.

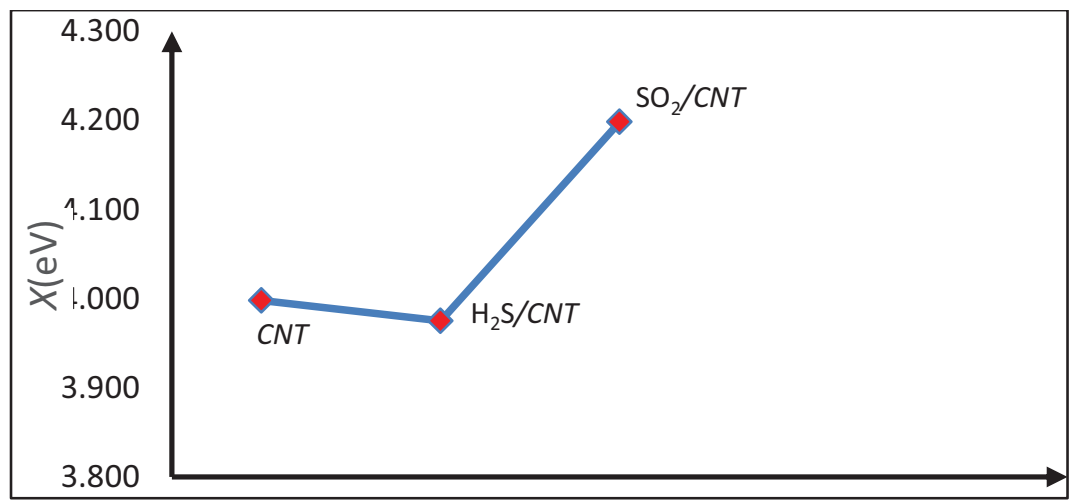

Fig. (8) The electronegativity in eV of the CNTs Sensors in this work.

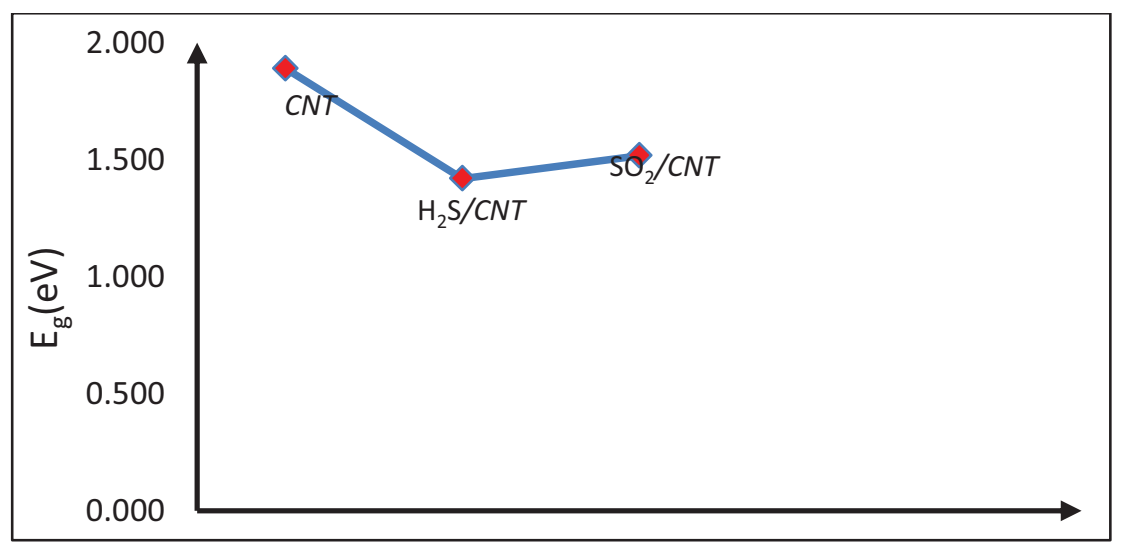

Fig. (9) The forbidden energy gap in $\mathrm{eV}$ of the CNTs Sensors in this work. 


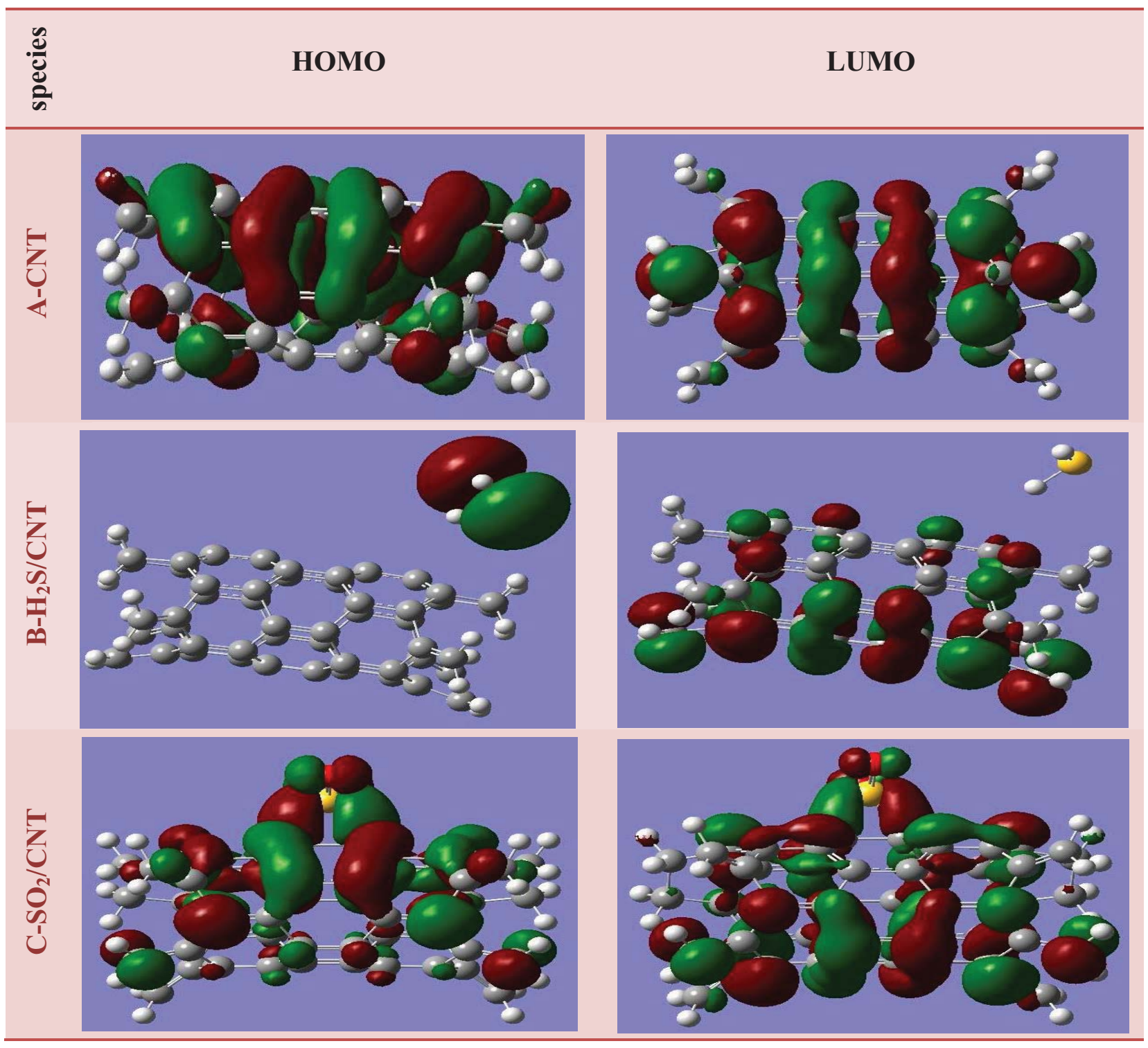

Fig. (10) The shapes of HOMO and LUMO for the CNTs Sensors in this work. 


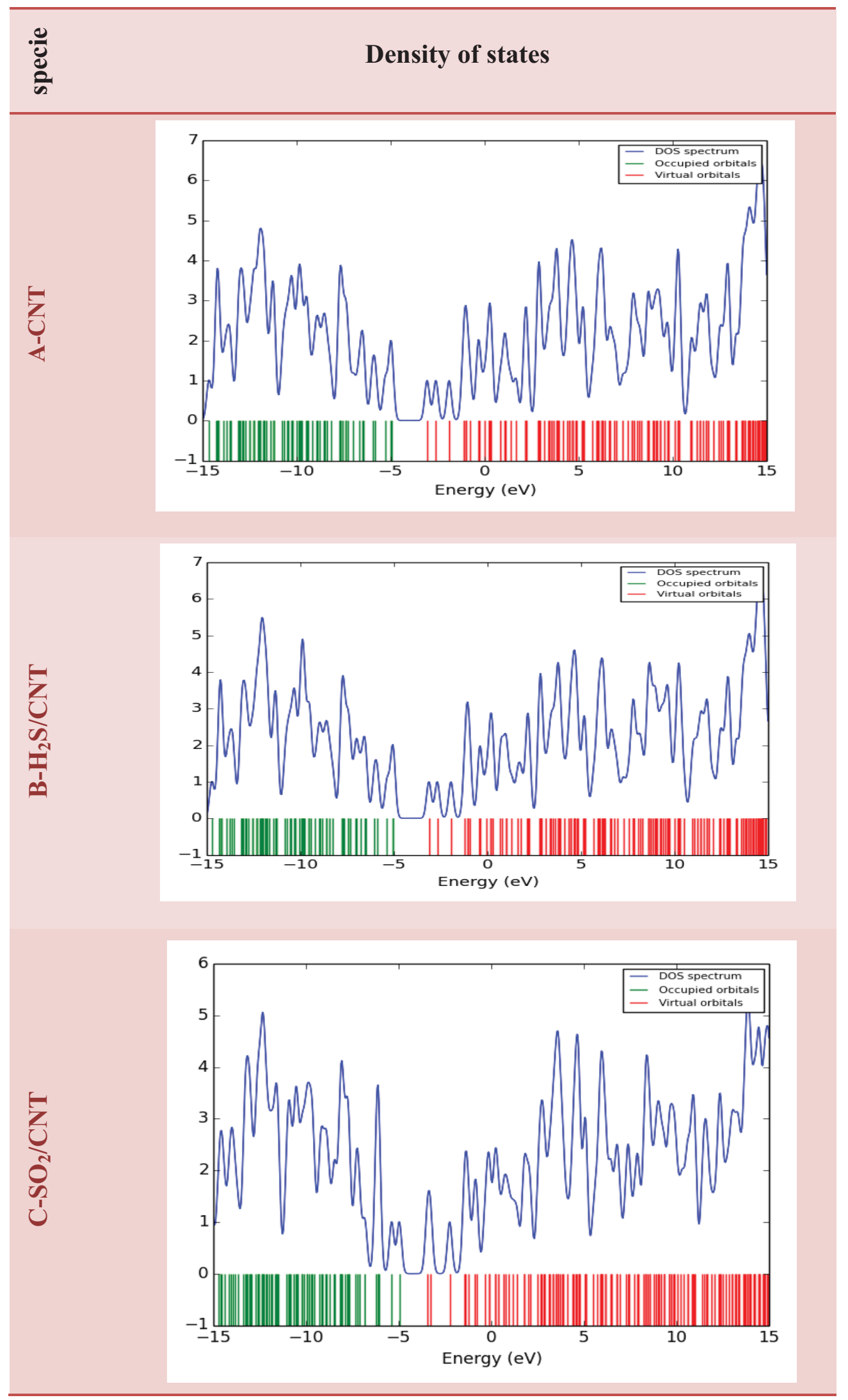

Fig. (11) The DOS the CNTs Sensors in this work. 


\section{Conclusions:}

we have utilize DFT in this contemplate should acquire the geometry optimization and calculate some electronic properties of CNTs Sensors using B3LYP hybrid functional. The calculated electronic properties such as ionization potential, electron affinity, electro negativity, hardness, softness by using orbital-vertical method, the important conclusions are:

1- Geometry optimization for molecule has been found to a great assention with test data, while for other studied molecules $\mathrm{SO}_{2} / \mathrm{CNT}$ and $\mathrm{H}_{2} \mathrm{~S} / \mathrm{CNT}$ it has not been found a reference data.

2- The total vitality $\mathrm{E}_{\mathrm{T}}$ of CNTs under stydy is very small, this result is a reflection of the binding energy of each structure.

3- The electronic properties (IP, EA, $\chi, \eta, S, \omega)$ was calculated by using orbital-vertical system would a great concurred upon with test effect.

4- The results indicate a decrease in the Eg values when sensing the gases. This is an indication of the approximation of the HOMO and LUMO values from each other and thus the possibility of electronic transitions between the valence and conductivity band, and a small energy gap means small excitation energies of manifold of the excited states.

5- The observed nonzero DOS demonstrates a limited number for states. Thus, $(5,0)$ SWCNT can be An guaranteeing nomination to identification the connected petroleum gas particles.

6- This type of sensor $\left(\mathrm{CNTs} / \mathrm{H}_{2} \mathrm{~S}\right.$ or $\left.\mathrm{SO}_{2}\right)$ may be a standout amongst personal protective equipment that is to warn the person of the vicinity of gasses connected with oil, especially in areas of normal gas extraction. 


\section{References:}

1. H. Dai, Carbon nanotubes: synthesis, integration, and properties. Accounts of chemical research, Vol.35, PP.1035-1044, 2002.

2. P. Ajayan, Nanotubes from carbon. Chemical reviews, Vol.99, PP.1787-1800, 1999.

3. J.Bernholc, D.Brenner, M.Buongiorno, V.Meunier, C.Roland, Mechanical and electrical properties of nanotubes. Annual Review of Materials Research, Vol.32, PP.347-375, 2002.

4. C.Dekker, Carbon nanotubes as molecular quantum wires. Physics today, Vol.52, PP.2230, 1999.

5. P. Avouris, J.Appenzeller, R. Martel, S. Wind, Carbon nanotube electronics. Proceedings of the IEEE, Vol.91, PP.1772-1784, 2003.

6. M. Dresselhaus, P.Avouris, Introduction to carbon materials research. InCarbon nanotubes, Springer Berlin Heidelberg, 2001.

7. M. Rittersma, Recent achievements in miniaturised humidity sensors-a review of transduction techniques, Sensors and Actuators A, Vol. 96, PP. 196-210, 2002.

8. S. Iijima, Helical microtubules of graphitic carbon, Nature, Vol. 354, PP. 56-58, 1991.

9. M. Meyyappan, Carbon Nanotubes: Science and Applications, CRC Press, Boca Raton, USA, 2004.

10. M. Dresselhaus, G. Dresselhaus and P. Eklund, Science of Fullerenes and Carbon Nanotubes, Academic Press, New York, NY, USA, 1996.

11. R. Saito, M. Fujita, G. Dresselhaus, and M. S. Dresselhaus, Electronic structure of chiral graphene tubules, Applied Physics Letters, Vol. 60, PP. 2204-2206, 1992.

12. [12] M. Dresselhaus, G. Dresselhaus, and P. Avouris, Carbon Nanotubes: Synthesis, Structure, Properties and Applications, Springer, Berlin, Germany, 2001.

13. [13] M. Yoosefian, Z. Barzgari, and J. Yoosefian, Ab initio study of Pd-decorated single-walled carbon nanotube with C-vacancy as CO sensor, Structural Chemistry, Vol. 25, PP. 9-19, 2014.

14. M. Frisch, G. Trucks, H. Schlegel, G. Scuseria, M. Robb, J. Cheeseman, G. Scalmani, V. Barone, B. Mennucci, G. petersson, H. Nakatsuji, M. Caricato, X. Hratchian, A. Izmaylov, J. Bloino, G. Zheng, J. Sonnenberg, M. Hada, M.Ehara, K. Toyota, R. Fukuda, J. Hasegawa, M. Ishid, T. Nakajima, Y. Honda, O. Kitao, H. Nakai, T. Vreven, J. Montgomery, J. E. Peralta, F. Ogliaro, M. Bearpark, J. Heyd, E. Brothers, K. Kudin, 
V. Staroverov, R. Kobayashi, J. Normand, K. Raghavacharii, A. Rendell, J. Burant, S. Iyengar, J. Tomasi, M. Cossi, N. Rega, J. Millam, M. Klene, J. Knox, J. Cross, V. Bakken, C. Adamo, J. Jaramillo, R. Gomperts, R. Stratmann, O. Yazyev, A. Austin, R. Cammi, C. Pomelli, J. Ochterski, R. Martin, K. Morokuma, V. Zakrzewski, G. Voth, P. Salvador, J. Dannenberg, S. Dapprich, A. Daniels, O. Farkas, J. Foresman, J. Ortiz, J. Cioslowski, and D. J. Fox, "Gaussian 09, revision A. 02 Gaussian", Inc Wallingford CT., 2009.

15. G. Robert, Parr, Yang and Weitao, Density Functional Theory of Atoms and Molecules, Oxford University Press, Oxford, 1994.

16. A. Bender, Structure modeling of aluminosil-sesquioxanes, Ph. D. Thesis, Berlin, Germany, 2000.

17. P. Romaniello, Time dependent current density functional theory for molecules, Ph.D. Thesis, Material Science Center, University of Groningeen, Netherlands, 2006.

18. 39J. Engelberts, R. Havenith, J.V. Lenthe, L. Jenneskens and P. Fowler, Computational and theoretical chemistry, Inorg. Chem, Vol. 44, 2005.

19. J. Santos, W. Tiznado, R. Contreras and P. Fuentealba, J. Chem. Phys, Vol.1670 2004.

20. Ali S. Hasan, Hamid I. Abbood, International Journal of Advanced Research, Vol.3, PP.1082-1089, 2015.

21. R. Gotwals and C. Sendlinger, A Chemistry Educator's Guide to Molecular Modeling (1st Edition), North Carolina School of Science and Mathematics Center, USA, 2008.

22. Ali S. Hasan, Hamid I. Abbood, Density Function Theory Calculations of Graphene Sheet, JOURNAL OF KUFA - PHYSICS, Vol.8, PP.65-69, 2016.

23. K. Sadasivam and R. Kumaresan, Computational and Theoretical Chemistry, J. Chem. Phys., Vol. 963, PP.235-227, 2011.

24. M. Oftadeh, S. Naseh and M. Hamadanian, Computational and theoretical chemistry، Chemical Physics Letters, Vol.966, PP.20-25, 2011.

25. L. YH, S.Wang, J.Wei, X. Zhang, C. Xu, Z. Luan, D. Wu, B. Wei. Lead adsorption on carbon nanotubes. Chemical Physics Letters, Vol.3,PP.357-263, 2002.

26. A.EL-Barbary, K. Eid, M. Kamel, H. Osman, G. Ismail, Journal of Surface Engineered Materials and Advanced Technology, Vol.4, PP.66-74, 2014. 
27. A. Ghasemi, M. Molla, International Journal of ChemTech Research, Vol.4, PP.13021308, 2012.

28. X. Zhang, H. Cui, Y. Gui, J. Tang, Mechanism and Application of Carbon Nanotube Sensors in SF6 Decomposed Production Detection: a Review, Nanoscale research letters, Vol.1, PP1-12, 2017.

29. B. Lone, Adsorption of Cytosineon Single-walled Carbon Nanotubes. J Nanomed Nanotechnol.Vol.2, PP.354, 2016. 